\title{
Investigation of factors affecting on viscosity reduction of sludge from Iranian crude oil storage tanks
}

\author{
Masoumeh Hassanzadeh $^{1} \cdot$ Leila Tayebi $^{1} \cdot$ Hedieh Dezfouli $^{1}$
}

Received: 27 May 2017/ Published online: 24 July 2018

(C) The Author(s) 2018

\begin{abstract}
Crude oil is a kind of water/oil emulsion, which the oil phase consists of organic molecules with different molecular weights such as alkanes, paraffin, asphaltene, and resins. Due to the change in physicochemical conditions during the production, transportation, storage, and refining, heavier molecules can precipitate from crude oil. Thus, viscous sludge formed at the bottom of storage tanks can cause many problems including reduction of storage capacity of tank, oil contamination, corrosion, repair costs, environmental pollution, etc. The reduction of sludge viscosity can be achieved by reduction of its interfacial tension. In this study, different chemical and physical factors, influencing prepared emulsions (made of sludge, water and surfactant), such as surfactants, solvents, temperature, pressure, and mixing conditions were investigated. Results showed that non-ionic surfactants (like bitumen emulsifier), and solvents (such as mixed xylene, AW400, and AW-402), injection of additives, applying pressure, and mixing operations had a positive effect on reduction of emulsion viscosity. All experiments were carried out with sludge obtained from crude oil storage tanks at Kharg Island, Iran.
\end{abstract}

Keywords Surfactant $\cdot$ Emulsion $\cdot$ Sludge $\cdot$ Storage tank $\cdot$ Crude oil

\section{Introduction}

Formation and deposition of crude oil sludge during oil production and refining operations (extracting, transporting, storage, and refinery processing) has received much attention in recent years.

According to an investigation conducted by U.S. EPA, each refinery in the USA produces an annual average of 30,000 tonnes of oily sludge (Hu et al. 2013). It is estimated that, in 2001, large oil refineries (processing $(2-5) \times 10^{5}$ barrels per day) in the USA, produced $10,000 \mathrm{~m}^{3}$ of sludge and in India about 50,000 tonnes. Total production of sludge goes up because of the increasing demand for refined petroleum products worldwide (Hu et al. 2013; Heath et al. 2004).

Edited by Xiu-Qin Zhu

Masoumeh Hassanzadeh

mhasanzad@ut.ac.ir; m.hassanzadeh96@aut.ac.ir

1 Chemical Process Design Research Group, ACECR, Faculty of Engineering, University of Tehran, Tehran, Iran
The sludge formation has adverse impacts for the oil companies due to some problems associated with it. These wastes lead to reducing the capacity of storage tanks, reducing the processing rate by disrupting the operations, blocking of tank discharge lines, having toxic effects for workers and accelerating corrosion. Additionally, improper disposal of sludge causes serious threats to the environment. However, the sludge should be considered as a valuable compound, since it can be recycled to the refineries to reuse recovered oil from the sludge, for processing and reformulating (See et al. 2015; Reynold and Heuer 1993; Nahmad Gandi 2009; Rocha et al. 2009).

The sludge found in crude oil storage tanks typically is made up of water, petroleum hydrocarbons, and solids. It forms when crude oil properties are changed due to several factors. Storage conditions, storage period, the composition of the crude oil, the amount of water and sediments, the temperature of the crude oil, and the mechanical conditions of the storage tanks represent the most common causes of sludge formation (Corti and Falcon 1989; Altunina and Svarovskaya 2012). Depending on the source of petroleum sludge, its composition can be quite varied, but typically, it is composed of $5 \%-90 \%$ hydrocarbon oil phase, $1 \%-52 \%$ 
water, and 0.8\%-86\% solid particles (Goulin et al. 2011; Mansur et al. 2015; Zhang et al. 2014; Monteiro et al. 2015; Lima et al. 2014). Sludges are produced by gradual settlement of heavy oil fractions such as asphaltene, paraffin, and solid particles; thus, they can be classified into asphaltene-based crude oil sludge, and paraffin-based crude oil sludge (Reynold and Heuer 1993; Woodrising Resources Ltd; McLean and Kilpatrick 1997; Jafari Behbahani et al. 2015).

Asphaltenes are heavy hydrocarbons that are in colloidal dispersion in the oil and are stabilized by resins adsorbed on their surface, thus the interaction between asphaltenes and resins results in the precipitation of asphaltenes (McLean and Kilpatrick 1997; Jafari Behbahani et al. 2015). Although the sludge formation is mainly attributed to the presence of asphaltene in crude oil, paraffin can also form paraffin-based crude oil sludge. This type of the sludge forms when the heavier straight-chain hydrocarbons (heavier than $\mathrm{C}_{20}$ ) flocculate. They accumulate on the bottom of the tank as a viscous gel, the concentration of which will increase by vaporizing the volatile components, and resulting in increased density and viscosity and decreased mobility (Reynold and Heuer 1993; Woodrising Resources Ltd).

Eventually, the sludge must be removed from storage tanks. Known methods of sludge removal involve oil recovery methods and disposal methods (Franco et al. 1996). Thermo-chemical methods, solvent extraction, froth flotation, pyrolysis, surfactant, ultrasonic irradiation, electro-kinetic methods, microwave irradiation, freeze/thaw, and centrifugation are known as oil recovery methods. Cleaning methods such as manual cleaning, robotic methods, biodegradation, oxidation, stabilization/solidification and incineration are known disposal methods ( $\mathrm{Hu}$ et al. 2013; Miyasaki 1997; Taiwo and Otolorin 2009; Jun et al. 2002; Ramaswamy et al. 2007; Strenkert and Carls 1969; Bock et al. 1990; Jing et al. 2012; Zhanga et al. 2013; Polycell products limited. BP 1964; Shie et al. 2004).

Use of surfactants for cleaning of wastes is a relatively fast process, which has the potential to treat large volumes. After mixing the sludge with solvents and surface-active agents, and then applying thermal and mechanical actions, sludge is converted to an emulsion, which causes viscosity reduction by reduction of interfacial tension. So sludge removing from storage tanks or other refinery apparatus becomes possible (Zubaidy and Abouelnasr 2010; Klier et al. 1998; Campbell 2002).

\section{Materials and methods}

\subsection{Materials}

Oil sludge used for this study was provided from Kharg Island in the south region of Iran (IRI). Crude oil and different petroleum distillates such as fuel oil, gas oil, and kerosene were provided by the National Iranian Oil Refining and Distribution Company (NIORDC). Mixed xylene, solvents AW-400 and AW-402 were provided by Esfahan oil refining (EOCR) and Esfahan petrochemical (EPC) companies. Various surfactants (ionic, non-ionic and amphoteric) such as bitumen emulsifier, sorbitan monooleate, poly sorbate, protonized lignin, coconut diethanol amide, potassium laurate, sodium cocoyl sarcosinate and alkyl betaine (all were synthesized by ACECR in lab or pilot scales), ethoxylated nonyl phenol (10 mol) (99\%, Kimyagaran Emrooz Co.), alkyl benzyl dimethyl ammonium chloride (98\%, Asalib Co.), sodium lauryl sulfate (30\%, Shopa Chemical Co.), dodecyl benzene sulfonate (EPC), were all used without any purification. Silica gel (60-100 mesh), alumina powder (100-125 mesh) and other solvents like pure xylene (99\%, BDH Chemical Ltd.), and toluene (99\%, EPC), $n$-heptane, di chloroethane (99\%, Applichem), and methanol (99.5\%, Mojallali Co.) were also used for experimental tests and analysis.

\subsection{Apparatus}

Viscosities were measured by an RV-DV2 Brookfield viscometer at ambient conditions $\left(\sim 25^{\circ} \mathrm{C}\right.$ and atmospheric pressure).

\subsection{Methods}

\subsubsection{Analysis of the sludge}

The main detection criterion for characterization of the sludge is the measurement of volatile and non-volatile hydrocarbons, water, and solids. Water content was measured by ASTM D-95 method. Light hydrocarbon (LH) and solid (ash) contents were determined by heating and calculating the reduced mass of sample. Non-volatile hydrocarbons (NVH) of the sludge were simply obtained by revealed water, $\mathrm{LH}$, and ash contents as below:

$\% \mathrm{NVH}=100-(\%$ water $+\% \mathrm{LH}+\%$ Solid $)$

Results are shown in Table 1.

Saturated, aromatics, resins, and asphaltene (SARA) are the main hydrocarbon fractions of the sludge.

The IP-143 standard method was carried out for measuring the asphaltene content with a Soxhlet system of toluene-heptane solvents. The non-asphaltene content was 
Table 1 Water, volatile, nonvolatile hydrocarbons and solids in the sludge

\begin{tabular}{lc}
\hline Components & Content, wt $\%$ \\
\hline Hydrocarbons & \\
Non-volatile & 90.48 \\
Volatile & 1.12 \\
Non-hydrocarbons \\
Water & 1.76 \\
Solids & 6.64 \\
\hline
\end{tabular}

analyzed through silica gel-alumina column chromatography using the ASTM D-2007 method. Results are shown in Table 2.

\subsubsection{Sludge emulsion preparation}

Since the sludge is a sticky and viscous semi-solid, at first it was emulsified and fluidized by water and emulsifier. For this purpose, certain amounts of water and a non-ionic surfactant as emulsifier were added to a known amount of the viscous sludge and gradually blended (Fig. 1). It required $30 \mathrm{~min}$ to $3 \mathrm{~h}$ for blending to obtain a homogeneous and uniform emulsion. However, in some cases, the time required for preparing an emulsion reached to 2-3 days.

\section{Results and discussion}

The crude oil is a W/O emulsion consisting of water, saturated and aromatic hydrocarbons with different molecular weights. Alkanes, cyclo alkanes, paraffin, waxes, benzene and its derivatives, asphaltenes, and resins are the oil phase of this emulsion. At ideal conditions, a homogeneous and stable liquid compound is formed by dissolving these molecules in each other. Over time, properties of the storage crude oil may be changed due to continued discharge from the tank, changes in temperature and weather, pressure variations, presence of oxidizing bacteria and fungi, etc. Additionally, light components may evaporate and cause changes in the overall composition of the crude oil, ratio of saturated to aromatics hydrocarbons, polarity and solubility of components and their density. Therefore,

Table 2 Hydrocarbon components (SARA) of the sludge

\begin{tabular}{lc}
\hline Hydrocarbon components & Content, wt\% \\
\hline Saturated hydrocarbons & 61.89 \\
Aromatic hydrocarbons & 10.70 \\
Resins & 8.99 \\
Asphaltenes & 18.42 \\
\hline
\end{tabular}

settlement of heavy components such as paraffins, asphaltenes, resins, and inorganic solids at the bottom of the storage tanks occurs. In this way, a viscous emulsion of sludge forms. This sticky and viscous emulsion of sludge is a W/O or O/W emulsion (on the basis of volume or mass fraction of oil and water and crude oil type) which consist of water, organic and inorganic components.

On the basis of Newton's law, viscosity is an important constant which is related to ratios of the shear rate and shear stress of different fluids. Hence, viscosity is an affecting factor on rheological properties of emulsions. Since emulsions have special rheological behavior over the other fluids, many factors such as discontinuous phase properties (molecular type and concentration), viscosity of the continuous phase, internal phase properties like presence of additives, volume fraction of phases, particle size, $\mathrm{pH}$ and etc. can affect the emulsion viscosity (Ghomashchi and Akbari 2008). High viscosity and stability of the sludge emulsion is due to these above mentioned factors. It should be noted that interfacial force is an outcome of the intermolecular forces such as van der Waals forces, hydrogen bonds and hydrophilic-lipophilic forces (Ghomashchi and Akbari 2008; Goulin et al. 2011; See et al. 2015). Hence, destabilization of sludge by adding solvents, surfactants or applying heat and mechanical forces can reduce the sludge viscosity and interfacial tension, so it converts to a pumpable fluid.

According to Tables 1 and 2, it is supposed that the viscous sludge is a paraffin-based compound. Experiments were designed in order to reduce viscosity considering factors including concentration of ingredients, different surfactants and co-surfactants, solvents, and other parameters such as temperature, pressure, mixing and the soaking time, which affect emulsion behavior.

\subsection{Effect of concentration of components}

As mentioned in Sect. 2.3.2, the sludge emulsion was formed by blending of the viscous sludge, water, and emulsifier (a non-ionic surfactant). The concentration of each component and reduction of interfacial tension are the main factors in formation of a perfectly homogeneous emulsion. To study the concentration effect, several tests were carried out with various amounts of the components, which are shown in Table 3.

In this way, in test nos. 1-3, the final emulsions are completely homogeneous with soft texture, high viscosity and stickiness. After $24 \mathrm{~h}$, no changes were observed in these samples. However, test nos. 4 and 5 were highly sticky and blending was too difficult. The final products were completely heterogeneous. The sludge emulsions in test nos. 6 and 7 were a little sticky. In both samples, a little 


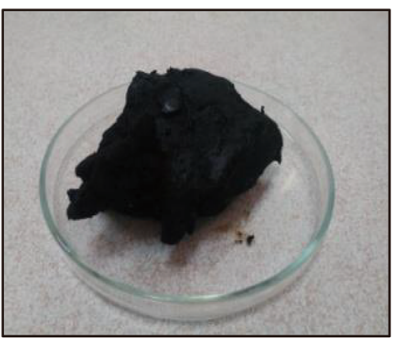

Viscose sludge

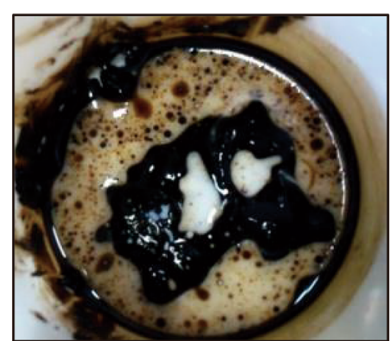

Mixture of components

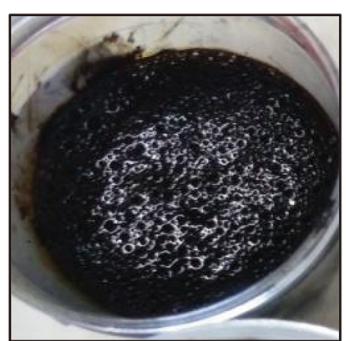

Sludge emulsion

Fig. 1 Preparation of the sludge emulsion

Table 3 The effect of concentration on sludge emulsion

\begin{tabular}{|c|c|c|c|c|c|c|c|}
\hline \multirow{2}{*}{$\begin{array}{l}\text { Test } \\
\text { no. }\end{array}$} & \multirow{2}{*}{$\begin{array}{l}\text { Sludge, } \\
\text { wt } \%\end{array}$} & \multirow{2}{*}{$\begin{array}{l}\text { Water, } \\
\text { wt } \%\end{array}$} & \multirow{2}{*}{$\begin{array}{l}\text { Emulsifier, } \\
\text { wt } \%\end{array}$} & \multirow[t]{2}{*}{ Viscosity, cp } & \multirow{2}{*}{$\begin{array}{l}\text { Temperature, } \\
{ }^{\circ} \mathrm{C}\end{array}$} & \multicolumn{2}{|l|}{ Observations } \\
\hline & & & & & & Appearance & Stability \\
\hline 1 & 70 & 20 & 10 & $\begin{array}{l}\text { Cannot be } \\
\text { measured }\end{array}$ & - & $\begin{array}{l}\text { Viscous sticky soft } \\
\text { texture }^{\mathrm{a}}\end{array}$ & Homogeneous \\
\hline 2 & 60 & 30 & 10 & $\begin{array}{l}\text { Cannot be } \\
\text { measured }\end{array}$ & - & $\begin{array}{l}\text { Viscous sticky soft } \\
\text { texture }^{\mathrm{a}}\end{array}$ & Homogeneous \\
\hline 3 & 50 & 40 & 10 & $\begin{array}{l}\text { Cannot be } \\
\text { measured }\end{array}$ & - & $\begin{array}{l}\text { Viscous sticky soft } \\
\text { texture }^{\mathrm{a}}\end{array}$ & Homogeneous \\
\hline 4 & 50 & 49.7 & 0.3 & $\begin{array}{l}\text { Cannot be } \\
\text { measured }\end{array}$ & - & High viscous sticky & Heterogeneous \\
\hline 5 & 50 & 49.4 & 0.6 & $\begin{array}{l}\text { Cannot be } \\
\text { measured }\end{array}$ & - & High viscous sticky & Heterogeneous \\
\hline 6 & 50 & 49.2 & 0.8 & 260.5 & 24.1 & A little viscous sticky & $\begin{array}{l}\text { Semi- } \\
\text { homogeneous }^{\mathrm{b}}\end{array}$ \\
\hline 7 & 50 & 48.8 & 1.2 & 263 & 23.6 & A little viscous sticky & $\begin{array}{l}\text { Semi- } \\
\text { homogeneous }^{\mathrm{b}}\end{array}$ \\
\hline
\end{tabular}

${ }^{a}$ Like creamy texture (Fig. 2)

${ }^{\mathrm{b}} \mathrm{A}$ little portion of the aqueous phase separates over time, but absorbs on remixing

portion of aqueous phase separated which absorbed on remixing (Fig. 2).

Observations are in accordance with emulsion theories that say the viscosity of an emulsion depends on many factors such as the viscosity of continuous and dispersed phases, the volume ratio of dispersed and continuous phases and properties of internal phase.

The sludge is a viscous and sticky emulsion, which consists of high volume percent of continuous phase (heavy molecules of paraffin, asphaltene, resin, etc.) with a high viscosity, and low volume percent of water molecules as the dispersed phase. Since the viscosity of the continuous phase is higher than the dispersed phase, the viscosity can be reduced by increasing the ratio of water to oil. Of course, the presence of emulsifier plays an important role in homogenization of the sludge and penetration of water molecules into the sludge texture. So, as the amounts of water and emulsifier increase, the emulsion becomes more homogeneous and uniform.
As see in Table 3, in test nos. 1-3, the emulsifier content is constant, and as the ratio of sludge to water becomes 1:1, they mix better, and the final product will have a soft cream-like texture (Fig. 2). It means that water can penetrate better between paraffin molecules. However, there is a significant difference between the softness of samples but unfortunately the viscosity of these emulsions cannot be measured at ambient conditions.

Likewise, in test nos. $4-7$, the ratio of sludge to water remained approximately constant and as the emulsifier (non-ionic surfactant) content increased, the mixture becomes more homogeneous and softer than before. This leads to a significant reduction of viscosity to about $260 \mathrm{cp}$.

In addition, results indicate that in test nos. 6 and 3, by increasing emulsifier concentration from 0.8 to $10 \mathrm{wt} \%$ and decreasing water content from 49.2 to $40 \mathrm{wt} \%$, a significant difference in their viscosity was observed. As said before, the ratio of sludge to water and the overall concentration of continuous phase (the sludge) are important 


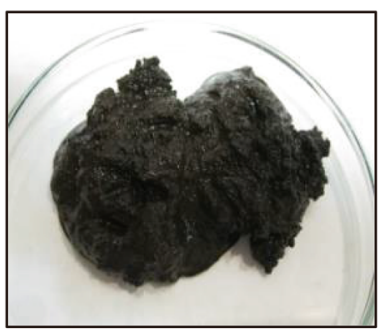

Sticky and viscose texture

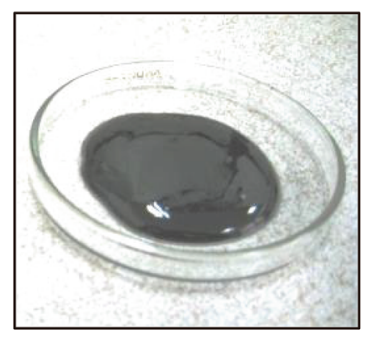

Soft texture

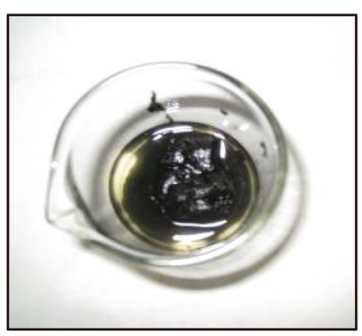

Heterogeneous texture

Fig. 2 Effect of component concentration on sludge behavior

Table 4 The effect of different solvents on the sludge emulsions

\begin{tabular}{|c|c|c|c|c|}
\hline \multirow[t]{2}{*}{ Test no. } & \multirow[t]{2}{*}{ Solvent } & \multirow[t]{2}{*}{ Content, wt $\%$} & \multicolumn{2}{|l|}{ Observations } \\
\hline & & & Appearance & Stability \\
\hline 1 & Water & 20 & Too viscous high sticky & Heterogeneous \\
\hline 2 & & 30 & Too viscous high sticky & Heterogeneous \\
\hline 3 & Crude oil & 20 & Too viscous high sticky & Semi-homogeneous ${ }^{a}$ \\
\hline 4 & & 30 & Too viscous high sticky & Semi homogeneous ${ }^{\mathrm{a}}$ \\
\hline 5 & Gas oil & 20 & High viscous high sticky & Heterogeneous \\
\hline 6 & & 30 & High viscous a little sticky & Semi homogeneous ${ }^{\mathrm{a}}$ \\
\hline 7 & Fuel oil & 20 & Too viscous sticky & Heterogeneous \\
\hline 8 & & 30 & Too viscous sticky & Heterogeneous \\
\hline 9 & Kerosene & 20 & A little viscous sticky & Heterogeneous \\
\hline 10 & & 30 & A little viscous sticky & Semi homogeneous ${ }^{\mathrm{a}}$ \\
\hline 11 & Pure xylene & 20 & A little viscous sticky & Heterogeneous \\
\hline 12 & & 30 & A little viscous sticky & Heterogeneous \\
\hline 13 & Toluene & 20 & A little viscous sticky & Heterogeneous \\
\hline 14 & & 30 & A little viscous sticky & Semi homogeneous ${ }^{\mathrm{a}}$ \\
\hline 15 & Mixed xylene & 20 & High viscous no stickiness & Semi homogeneous ${ }^{\mathrm{a}}$ \\
\hline 16 & & 30 & High viscous no stickiness & Homogeneous \\
\hline 17 & $\mathrm{AW}-400$ & 20 & High viscous a little sticky & Semi homogeneous ${ }^{\mathrm{a}}$ \\
\hline 18 & & 30 & High viscous no stickiness & Semi homogeneous ${ }^{\mathrm{a}}$ \\
\hline 19 & AW-402 & 20 & A little viscous sticky & Semi homogeneous ${ }^{\mathrm{a}}$ \\
\hline 20 & & 30 & A little viscous sticky & Homogeneous \\
\hline
\end{tabular}

${ }^{\mathrm{a}} \mathrm{A}$ little portion of aqueous phase separates over time, but absorbs on remixing factors in viscosity. Therefore, as seen, because of higher overall content of the sludge, despite high emulsifier concentration in test no. 3, the final emulsion is sticky and viscous so the viscosity cannot be measured. Additionally, in test nos. 3 and 6 , the sludge to water ratio is 50/40 and $50 / 49.2$, respectively. So, the viscosity of test no. 6 should be lower than test no. 3. On the other hand, in test nos. 6 and 7 , as emulsifier content increases and water content decreases, the viscosity increases a little from 260.5 to $263 \mathrm{cp}$ because of a little high overall sludge content in test no. 7.

\subsection{Effect of solvents}

First, the sludge emulsions were prepared by mixing of $50 \mathrm{wt} \%$ sludge, $49.2 \mathrm{wt} \%$ water, and $0.8 \mathrm{wt} \%$ emulsifier. Then, to investigate the synergistic effect of solvents on viscosity reduction of sludge, the second sludge emulsions were prepared by twenty and thirty weight percent of different solvents (Table 4). After solvent addition, in 28\% secondary emulsions there is $40 \mathrm{wt} \%$ sludge, $39.34 \mathrm{wt} \%$ water, and $0.66 \mathrm{wt} \%$ emulsifier. Similarly, in thirty weight percent secondary emulsions, there is $35 \mathrm{wt} \%$ sludge, $34.45 \mathrm{wt} \%$ water, and $0.55 \mathrm{wt} \%$ emulsifier. After the solvent addition, most of the samples were become too sticky 


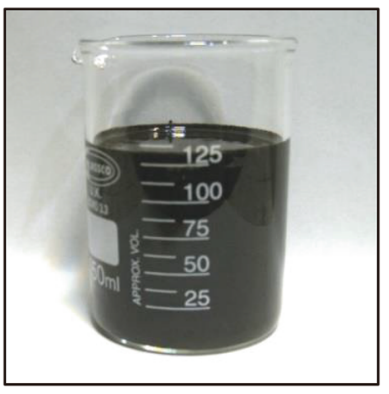

Mono phase product (Initial time)

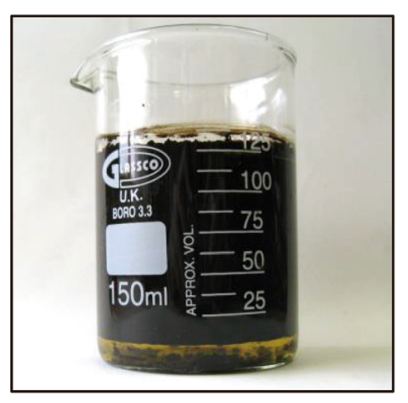

Two phases product (After 24 hours)
Fig. 3 The effect of solvents on sludge behavior

and viscous. The aqueous phase separated over time and the final products were heterogeneous (Fig. 3). Only in test nos. 15, 16 and 20 was the aqueous phase absorbed completely into the sludge texture. The stickiness decreased significantly and the sludge emulsions were homogeneous with a soft texture. Results are shown in Table 4.

On the basis of Table 4, by adding water as a solvent, the ratio of water to oil phase changed in the new emulsion, so emulsifier concentration decreased as well. Therefore, an emulsion inversion occurred and subsequently the attractive forces between water and paraffin molecules decreased. In this manner, the stickiness and flocculation of the emulsion was increased.

By addition of crude oil to the primary sludge emulsion as an organic solvent, the single-phase mixture converts into a two-phase one. In final products, the sludge lay in the upper part of mixture as a viscous and sticky layer (Fig. 3). Unfortunately, the viscosity did not reduce as well.

With gas oil as a solvent, distinct results were obtained. At $20 \mathrm{wt} \%$ gas oil, a two-phase product formed, which was viscous and sticky, but by $30 \mathrm{wt} \%$ gas oil a uniform and fluid mixture was produced, however, it became two-phase over time.

In the presence of fuel oil, as an organic solvent the same results were obtained. The final product was twophased with high viscosity and stickiness.

Similar results were observed by kerosene, toluene, and pure xylene. Unfortunately, because of separation of aqueous phases and increasing stickiness, their viscosity could not be measured at room temperature. Therefore, the exact differences of these solvents cannot be determined.

In the same manner, when adding $20 \mathrm{wt} \%$ of mixed xylene, solvents AW-400 and AW-402 the final products were again inhomogeneous and the aqueous phase separated over time. However, a significant reduction of viscosity developed with the addition of $30 \mathrm{wt} \%$ of these solvents. According to the observations and appearance of the final products, solvents could be ranked based on their influence on fluidity and viscosity reduction of the emulsion, as follows:

Mixed xylene $>$ toluene $>$ AW $-402 \geq$ AW -400

$>$ pure xylene $>$ crude oil $>$ gas oil $>$ fuel oil

As explained at the beginning of this section, in final products, the weight percent of the viscous sludge, water, and emulsifier changed by adding solvent. Therefore, the formulation of the continuous phase changed and the viscosity of the continuous and dispersed phases shifted. According to our results and observations, it seems that the presence of non-polar solvents can help to increase the penetration of surfactant molecules into the aqueous and oil phases; therefore, the fluidity of sludge increased. These solvents are more compatible with alkane and paraffin components, which exist in paraffin-based sludge. In this way, the best results were obtained by mixed xylene, toluene and solvent AW-402. However, due to complexity of intermolecular forces, interfacial tension, etc., it is too difficult to describe the relationship between viscosity and these variations.

\subsection{Effect of surfactants}

Surfactants are an important part of an emulsion, as they can mix two immiscible phases by lowering the interfacial tension. Surface-active agents (surfactants) are organic compounds with hydrophilic-hydrophobic characteristics that homogenize a mixture by making a bridge on the interface of two phases (oil and aqueous phase). Therefore, surfactants play a key role in producing a homogeneous sludge emulsion when diluted by water or other solvents. In previous tests, the sludge emulsions were prepared in presence of bitumen emulsifier. In this section, several anionic, non-ionic, and amphoteric surfactants in the same concentration $(0.8 \mathrm{wt} \%)$ used to investigate the efficiency of surfactants on the reduction of viscosity. Results are shown in Table 5.

Results show that, stickiness of the sludge was decreased by the bitumen emulsifier, and it became softer with a homogeneous and uniform texture. However, a portion of aqueous phase separated over time, which absorbed on remixing. Despite bitumen emulsifier, among the non-ionic surfactants, stickiness and viscosity of sludge emulsions were increased by sorbitan monooleate and poly sorbate $(80 \mathrm{~mol})$ too, although the bitumen emulsifier worked better than all these other surfactants. Additionally, in presence of ethoxylated nonyl phenol, dodecyl benzene sulfonate, and alkyl betaine surfactants, more foam bubbles were created among the sludge particles by mixing, and hence the sludge texture became puffy. 
Table 5 The effect of surfactants on stability and viscosity of the sludge emulsion

\begin{tabular}{|c|c|c|c|c|}
\hline \multirow[t]{2}{*}{ Test no. } & \multirow[t]{2}{*}{ Surfactant type } & \multirow[t]{2}{*}{ Surfactant name } & \multicolumn{2}{|l|}{ Observations } \\
\hline & & & Appearance & Stability \\
\hline 1 & Non-ionic & Bitumen emulsifier & A little viscous sticky & Semi homogeneous ${ }^{\mathrm{a}}$ \\
\hline 2 & & Sorbitan monooleate & A little viscous sticky & Homogeneous \\
\hline 3 & & Poly sorbate 80 & Too viscous sticky & Heterogeneous \\
\hline 4 & & Ethoxylated nonyl phenol $(10 \mathrm{~mol})$ & Too viscous sticky puffy texture ${ }^{b}$ & Heterogeneous \\
\hline 5 & Cationic & Protonized lignin & Too viscous sticky & Heterogeneous \\
\hline 6 & & Alkyl benzyl dimethyl ammonium chloride & Too viscous sticky & Heterogeneous \\
\hline 7 & Anionic & Potassium laurate & Too viscous sticky & Heterogeneous \\
\hline 8 & & Sodium lauryl sulfate & Too viscous sticky puffy texture ${ }^{b}$ & Heterogeneous \\
\hline 9 & & Dodecyl benzene sulfonate & Too viscous sticky puffy texture ${ }^{\mathrm{b}}$ & Heterogeneous \\
\hline 10 & & Sodium cocoyl sarcosinate & Too viscous sticky & Heterogeneous \\
\hline 11 & Amphoteric & Alkyl betaine & Too viscous sticky puffy texture ${ }^{b}$ & Heterogeneous \\
\hline
\end{tabular}

${ }^{\mathrm{a}} \mathrm{A}$ little portion of aqueous phase separates over time, but absorbs by remixing

${ }^{\mathrm{b}}$ Foam bubbles create by mixing and set among the sludge particles

Anionic, cationic, and amphoteric surfactants also increased the stickiness and viscosity and are not suitable for preparing homogeneous and uniform products. However, they convert the sludge to a softer texture, but an acceptable condition was not achieved. So the viscosity reduction cannot be measured at room temperature due to sample heterogeneity and their high stickiness and viscosity.

From these results, one can conclude that the function and application of a surfactant related to many emulsion parameters such as surfactant type and its concentration, the amount of water and solvent, molecular structure of compounds, age of the emulsion and distribution of surfactant molecules into the sludge mass.

As the paraffin-based sludge is formed by alkane and paraffin components, it seems that this kind of sludge is more compatible with bitumen emulsifier. It can be supposed that a better interaction can be created between the sludge particles and surfactant molecules due to the presence of similar types of non-polar and van der Waals forces.

\subsection{Effect of co-surfactants}

Typically, a mixture of the main surfactant and co-surfactant can be used in formulation of emulsions, to achieve synergistic effects and promote surfactants efficiency. For investigating the effect of co-surfactants, new sludge emulsions consisting of $0.5 \mathrm{wt} \%$ bitumen emulsifier (main surfactant) along with $0.3 \mathrm{wt} \%$ of other surfactants (as cosurfactant) were prepared. The results of co-surfactant efficiency are shown in Table 6.

In all samples, the final product remained sticky and viscous. The aqueous phase separated over time. Except in the case potassium laurate, foam bubbles were created during mixing. The bubbles were distributed among the

Table 6 The effect of co-surfactants on stability of sludge emulsions

\begin{tabular}{|c|c|c|c|}
\hline \multirow[t]{2}{*}{ Test no. } & \multirow[t]{2}{*}{ Co-surfactant } & \multicolumn{2}{|l|}{ Observations } \\
\hline & & Appearance & Stability \\
\hline 1 & Ethoxylated nonyl phenol $(10 \mathrm{~mol})$ & Viscous sticky puffy texture ${ }^{b}$ & Heterogeneous \\
\hline 2 & Potassium laurate & A little viscous sticky & Semi homogeneous ${ }^{\mathrm{a}}$ \\
\hline 3 & Sodium lauryl sulfate & Too viscous sticky puffy texture ${ }^{b}$ & Heterogeneous \\
\hline 4 & Dodecyl benzene sulfonate & Viscous sticky puffy texture ${ }^{b}$ & Heterogeneous \\
\hline 5 & coconut diethanol amide & A little viscous sticky puffy texture ${ }^{b}$ & Semi homogeneous ${ }^{\mathrm{a}}$ \\
\hline
\end{tabular}

${ }^{\mathrm{a}} \mathrm{A}$ little portion of aqueous phase separates over time, but absorbs on remixing

${ }^{\mathrm{b}}$ Foam bubbles created by mixing among the sludge particles 
Table 7 The effect of temperature on the sludge emulsion

\begin{tabular}{llllll}
\hline Test no. & Water temperature, ${ }^{\circ} \mathrm{C}$ & Viscosity, cp & Temperature, ${ }^{\circ} \mathrm{C}$ & & Observations \\
\cline { 3 - 6 } & & & Appearance & Stability \\
\hline 1 & 25 & 260.5 & 24.1 & Sticky & Semi homogeneous ${ }^{\mathrm{a}}$ \\
2 & $70-80$ & 258.3 & 23.8 & A little sticky & Semi homogeneous ${ }^{\mathrm{a}}$ \\
\hline
\end{tabular}

${ }^{\mathrm{a}} \mathrm{A}$ little portion of aqueous phase separates over time, but absorbs on remixing

sludge particles so puffy inhomogeneous mixtures were obtained. Hence, in all cases, the viscosity could not be measured at room temperature.

According to this, any of the co-surfactants worked well for viscosity reduction. Solubility of co-surfactants and their synergistic effects for reducing viscosity and increasing emulsification may be affected by other parameters such as solvent type and polarity.

\subsection{Effect of temperature}

Ordinarily, viscosity decreases with increasing temperature. The sludge texture is softened by heat and the sludge emulsion is conveniently and rapidly broken. Several tests were carried out to investigate the effect of heat on softening and fluidity of sludge. The sludge emulsions were prepared by $50 \mathrm{wt} \%$ sludge, $0.5 \mathrm{wt} \%$ bitumen emulsifier, and $49.5 \mathrm{wt} \%$ water. Results are shown in Table 7.

According to results, in test no. 1, the sludge was like a sticky paste and the aqueous phase separated over time. Hot water facilitated agitation, and the sludge was emulsified more easily than before. The separation of the aqueous phase was less than test no. 1 .

It seems that, heat has positive effects on softening of sludge, preparation of emulsion and reducing the viscosity of the final product. The interface properties of the two phases, the shape and the size of dispersed phase may be changed by heat. In paraffinic sludge, the movement of paraffin molecules increased by heating, so, they were rapidly softened and melted. Finally, the sludge structure was broken quickly. Heating along with mechanical forces (such as blending), can reduce the contact time of sludge particles and solvent molecules so the sludge emulsion could be prepared as quickly as possible.

\subsection{Effect of soaking time}

Soaking time is the time that water and emulsifier need to penetrate between the sludge particles. To investigate the effect of this, several sludge emulsions were prepared by $50 \mathrm{wt} \%$ sludge, $0.5 \mathrm{wt} \%$ bitumen emulsifier, and $49.5 \mathrm{wt} \%$ water, and set to rest for different time durations. The observation and results are illustrated in Table 8.

According to Table 8, one can see that penetration of the aqueous phase (water and emulsifier solution) between the sludge particles was increased over time. Therefore, the sludge texture wetted and gradually became softer than before. After 11 days, the stickiness of the sludge reduced, it could be conveniently agitated and emulsified as quickly as possible. It became more homogeneous and uniform than the other samples. However, it can be concluded that all samples needed to be agitated to disperse the sludge aggregates in the aqueous phase until a homogeneous and uniform emulsion was obtained. It seems that 4 days of soaking is more desirable and enough to allow water and surfactant molecules penetrate into the thick and sticky mass of the sludge for easy and fast admixing.

\subsection{Effect of pressure}

The synergy of heating and applying pressure (injection of fluidizing agents) during preparation of sludge emulsion
Table 8 The effect of soaking time on behavior of sludge emulsion

\begin{tabular}{llll}
\hline Test no. & Soaking time & Observations & \\
\cline { 3 - 4 } & & Appearance & Stability \\
\hline 1 & $2 \mathrm{~h}$ & Too viscous sticky & Heterogeneous \\
2 & 1 day & Too viscous sticky & Heterogeneous \\
3 & 4 days & A little viscous sticky & Semi homogeneous $^{\mathrm{a}}$ \\
4 & 8 days & A little viscous sticky & Semi homogeneous $^{\mathrm{a}}$ \\
5 & 11 days & A little viscous sticky & Semi homogeneous $^{\mathrm{a}}$ \\
\hline
\end{tabular}

${ }^{\mathrm{a}} \mathrm{A}$ small portion of aqueous phase separates over time but absorbs on remixing 
Table 9 The effect of mixing on sludge emulsion

\begin{tabular}{lllll}
\hline Test no. & Mixing conditions & Mixing time, min & Observations & Stability \\
\cline { 5 - 5 } & & & Appearance & Heterogeneous \\
2 & No mixing & - & Too viscous sticky & Semi homogeneous ${ }^{\text {a }}$ \\
3 & Manual mixing & 30 & A little viscous sticky & Semi homogeneous \\
\hline
\end{tabular}

${ }^{a} \mathrm{~A}$ little portion of aqueous phase separates over time, but absorbs by remixing

was investigated. It was revealed that applying pressure and heat had more desirable and adequate results as the sludge became soft and homogeneous more quickly. The synergistic effect of pressure, heat and mixing is due to increase in molecular collisions with high energy, increase in diffusion of molecules into the sludge mass, and better mixing of emulsion. Preparation of emulsion by introducing components without any pressure was more difficult.

\subsection{Effect of mixing}

Often a homogenizer needs to use for preparing high viscosity emulsion. In this work, the effect of mixing conditions was investigated. The sludge emulsions formulation consists of $50 \mathrm{wt} \%$ sludge, $0.5 \mathrm{wt} \%$ bitumen emulsifier, and $49.5 \mathrm{wt} \%$ water. The results and observations are represented in Table 9.

On the basis of observations, it is obvious that mixing could make a more uniform and homogeneous emulsion within a shorter time. In fact, the mechanical energy of mixer could increase the distances between molecular layers by creating shear stress in the fluid, so the intermolecular forces were decreased and the viscosity might be reduced.

\section{Conclusion}

The viscous sludge from precipitation of heavy molecules of crude oil including paraffin, asphaltene, and resin, at the bottom of storage tanks may cause many problems, with significant economic loss. By investigation of effective factors on reduction of viscosity, pumpable sludge emulsion can be prepared; thus, cleaning of the petroleum storage tanks can easily be performed. The findings of this work can be summarized as below:

(1) Sludge emulsions were prepared by viscous sludge, water and surfactant. We achieved this purpose by using of about $1: 1$ ratio of the viscous sludge to water and optimized the emulsifier concentration at $0.5-1 \mathrm{wt} \%$.
(2) Petroleum distillates used as solvents to increase solubility and decrease interfacial tension. Mixed xylene, and solvents AW-400 and AW-402 had the best influence on viscosity reduction of the sludge emulsion.

(3) Non-ionic surfactant (bitumen emulsifier) showed the best result among tested surfactants. It can be adsorbed at the interface of the oil and water phases as well and produces a homogeneous and uniform emulsion through reduction of interfacial tension.

(4) Perhaps it would be possible to check accurately the effects of co-surfactants by surface tension measurement. But in this work, the effects of different factors have been investigated on the basis of viscosity of the emulsions. In this manner, the co-surfactants did not show any distinct effects on viscosity changes.

(5) Physical operations such as increasing temperature of solvents soaking, and injection of solvent (applying pressure) cause appropriate effects on preparation of a uniform and homogeneous emulsion. They can also reduce the time needed for preparing the emulsion.

Acknowledgement The authors express their sincerest thanks to R\&D department, operation and utilization units of Kharg Oil Terminal Co. for providing us with the sludge from the crude oil storage tanks.

Open Access This article is distributed under the terms of the Creative Commons Attribution 4.0 International License (http://creative commons.org/licenses/by/4.0/), which permits unrestricted use, distribution, and reproduction in any medium, provided you give appropriate credit to the original author(s) and the source, provide a link to the Creative Commons license, and indicate if changes were made.

\section{References}

Altunina LK, Svarovskaya LI. Detergent composition for oil sludge reclamation. Pet Chem. 2012;52(2):130-2.

Bock J, Robbins ML, Canevari GP. Unique and effective separation technique for oil contaminated sludge. Patent US 4,938,877. 1990.

Campbell G. Sludge liquefaction process and agent. Patent US 6,440,330. 2002. 
Corti A, Falcon JA. Method and apparatus for treatment of oilcontaminated sludge. Patent US 4,812,225. 1989.

Franco ZD, Khalil CN, Pereira JOD. Process for the thermochemical cleaning of storage tanks. Patent US 5,580,391. 1996.

Ghomashchi T, Akbari Z. Principle of emulsion technology. Tehran: University of Tehran Press; 2008.

Goulin J, Tingting C, Mingming L. Studing oily sludge treatment by thermochemistry. Arab J Chem. 2011;9:s457-60.

Heath GM, Heath RA, Dundr Z. Paraffinic sludge reduction in crude oil storage tanks through the use of shearing and resuspension. Acta Montan Slovaca. 2004;9(3):184-8.

Hu G, Li J, Zengb G. Recent development in the treatment of oily sludge from petroleum industry: a review. J Hazard Mater. 2013;261:470-90.

Jafari Behbahani T, Ghotbi C, Taghikhani V, Shahrabadi A. Experimental study and mathematical modeling of asphaltene deposition mechanism in core samples. Oil Gas Sci Technol Rev IFP Energies Novellas. 2015;70(6):1051-74.

Jing G, Luan M, Du W, Han C. Treatment of oily sludge by advanced oxidation process. Environ Earth Sci. 2012;67:2217-21.

Jun MK, Seog YD, Hyo CC, Taec J, Won KJ, Kil PS. Method for removing sludge in crude oil tank and recovering oil there from. Patent US 2,002,153,279. 2002.

Klier J, Tucker CJ, Strandburg GM. High water content, low viscosity, oil continious micro emulsions and emulsions, and their use in cleaning applications. Patent US 5,811,383. 1998.

Lima CS, et al. Analysis of petroleum oily sludge produced from oilwater separator. Rev Virtual Quim. 2014;6(5):1160-71.

Mansur AA, Pannireselvam M, Al-Hothaly KA, Adetutu EM, Ball AS. Recovery and characterization of oil from waste crude oil tank bottom sludge from Azzawiya oil refinery in Libya. J Adv Chem Eng. 2015;5:118. https://doi.org/10.4172/2090-4568. 1000118.

McLean JD, Kilpatrick PK. Effects of asphaltene solvency on stability of water-in-crude oil emulsions. J Colloid Interface Sci. 1997;189(2):242-53.

Miyasaki MT. Method and apparatus for recovering the fuel value of crude oil sludge. Patent US 5,653,865. 1997.
Monteiro M, Svet V, Sandilands D, Tsysar S. Experimental investigation of various methods of sludge measurements in storage oil tanks. Adv Remote Sens. 2015;4:119-37.

Nahmad Gandi D. Method to recover crude oil from sludge or emulsion. United States of America Patent 2,009,223,858. 2009.

Polycell products limited, a British company, Improvement relating to the cleaning of the surfaces of oil tanks and other oil contaminated surfaces. Patent GB 951,618. 1964.

Ramaswamy B, Kar DD, De S. A study on recovery of oil from sludge containing oil using froth floating. J Environ Manage. 2007;85:150-4.

Reynold VR, Heuer SR. Process for the recovery of oil from waste oil sludge. United States of America Patent US 5,269,906. 1993.

Rocha NO, Khalil CN, Leite LF, Goja AM. Thermochemical process to remove sludge from storage tanks. Soc Pet Eng SPE. 2009;4:97-102.

See $\mathrm{CH}$, Saphanuchart W, Looi MH, Chong YL. Method of removing oil sludge and recovering oil from oil sludge with nanoemulsion surfactant system. United States of America Patent US 2,015,068,950. 2015.

Shie JL, et al. Oxidative thermal treatment of oil sludge at low heating rate. Energy Fuel. 2004;18(5):1272-81.

Strenkert LA, Carls WH. Method of cleaning large storage tanks for petroleum products. Patent US 3,436,263. 1969.

Taiwo EA, Otolorin J. Oil recovery from petroleum sludge by solvent extraction. Pet Sci Technol. 2009;27:836-44.

Woodrising Resources Ltd. Paratene ${ }^{\mathrm{TM}}$ sludge fluidization and recovery. Technical report, 2005.

Zhang K, Zhu J, Zhou Y, Wu B. Analysis thr fry-drying process of oily sludge sample. Chem Eng Res Des. 2014;92:2396-403.

Zhanga J, Lia J, Thringa R, Liub L. Application of ultrasound and Fenton's reaction process for the treatment of oily sludge. Proc Environ Sci. 2013;18:686-93.

Zubaidy EAH, Abouelnasr DM. Fuel recovery from waste oily sludge using solvent extraction. Process Saf Environ Prot. 2010;88(5):318-26. 